\title{
Barriers to HIVIAIDS Treatment in Nigeria
}

\author{
Jalal-Eddeen Abubakar Saleh", Haruna Ismaila Adamu
}

World Health Organization, Bauchi Zonal Office, Bauchi State, Nigeria

Email address:

drjalals@yahoo.com (Jalal-Eddeen A. S.)

\section{To cite this article:}

Jalal-Eddeen Abubakar Saleh, Haruna Ismaila Adamu. Barriers to HIV/AIDS Treatment in Nigeria. American Journal of Health Research. Vol. 3, No. 5, 2015, pp. 305-309. doi: 10.11648/j.ajhr.20150305.17

\begin{abstract}
Background: With the exception of South Africa and India, the number people living with Human Immunodeficiency Virus (PLWHA) in Nigeria exceeds that of any other country in the World. Access to HIV/AIDS treatment services remains a challenge as only $6 \%$ of PLWHAs have accessed the services. This stands in the way of achieving the National HIV/AIDS policy as well as the global goal of placing 15 million PLWHAs on treatment and care by the end of the year 2015. In order to achieve these goals, there is need to know the barriers (through systematic literature review) that prevent access to HIV/AIDS treatment especially in the developing world of sub-Saharan Africa (of which Nigeria is among) that houses $70 \%$ of global HIV/AIDS burden. When these barriers are known, strategies would then be adopted to remove them so as to improve the treatment coverage. Study Design: Systematic review. Methods: Twenty studies looking at issues surrounding barriers preventing access to HIV/AIDS treatment and support services in Nigeria and other developing countries were reviewed in order to identify key issues or barriers militating against the smooth delivery of HIV/AIDS treatment services and recommend strategies for removing them in order to achieve the much desired universal access to HIV treatment. Results: Suggest that the barriers to HIV/AIDS treatment in the developing world are grouped into three categories namely health systems related, patients related and community related. Conclusion: Sequel to the literature review findings, stakeholders must come together and agree on a sustainable and community driven approach to HIV/AIDS treatment in Nigeria.
\end{abstract}

Keywords: HIV, AIDS, ARV, ART, Barriers, Nigeria, Sub-saharan Africa, Low-Mid Income Countries

\section{Introduction}

With the exception of South Africa and India, the number people living with Human Immunodeficiency Virus (HIV) in Nigeria exceeds that of any other country in the World. ${ }^{1}$ HIV (Human Immunodeficiency Virus) causes AIDS (Acquired Immunodeficiency Syndrome) and once infected, the human body cannot get rid of it, so it stays there for life. ${ }^{2}$ Such a HIV-positive individual may appear healthy but still transmit the virus to healthy individuals in the society. ${ }^{3}$

HIV virus originated in the late 1800 s from a West African chimpanzee which harbored and transmitted simian immunodeficiency virus, SIV, to humans as a result of hunting and other means of contact with their infected blood. ${ }^{2}$ The SIV then mutated into HIV while in humans and began to spread across Africa and later into other parts of the world through mediums such as blood, semen, breast milk, and vaginal secretions. Contrary to some beliefs, there has so far been no evidence that the virus is transmitted as a result of kissing, hugging, shaking hands, or sharing personal objects, food or water. ${ }^{2}$ As soon as it gets into the body, the virus begins to destroy CD4 or T cells in the immune system, and soon the body becomes unable to fight infections and diseases that otherwise it would, setting the stage for the development of full blown AIDS. The period from the initial infection to the stage of AIDS could be from 2 to 15 years. ${ }^{4}$

An infected individual may or may not show signs and symptoms which include, but not limited to: fever, enlarged lymph glands, skin rash, sore throat, persistent diarrhea, cough, severe weight loss, fatigue, skin lesions and loss of appetite, depending on the stage of the infection. ${ }^{4}$ Without treatment, the infection may progress into advanced stage characterized by severe illnesses such as tuberculosis, fungal (cryptococcal) meningitis, and cancers such as lymphomas and Kaposi's sarcoma. $^{4}$

Medically speaking, the presence of HIV virus in the body can be detected by immunological tests that demonstrate the presence or absence of HIV antibodies in the blood. Unfortunately, a complete cure for HIV infection is yet to be found except to reduce the viral load with antiretroviral (ARV) drugs, a therapy which restores health and productivity to an otherwise hopeless infected individuals. ${ }^{4}$ Consequently, efforts 
towards preventing healthy persons from becoming infected with HIV virus become critical and mandatory if this scourge is to be controlled as a public health problem. The use of male and female condoms, testing and counselling for HIV and STIs and voluntary medical male circumcision have been proven scientifically as the key preventive measures against HIV infection. $^{4}$

The treatment of HIV/AIDS clients with ARV is part of the continuum of support and care rendered to those infected with the virus. Globally speaking, a total of 11.7 million people received ARVs as at December 2013. ${ }^{5}$ This means that the global target of covering 15 million people with ARVs is achievable. This good news is not so at the regional and country levels where, in the African Region, for instance, only $37 \%$ of people living with HIV were able to access lifesaving medicines that year. ${ }^{5}$ The picture is even more gloomy at the country level where the ARV coverages were $22 \%, 6 \%, 6 \%, 6 \%$ in South Africa, Zimbabwe, Kenya and Nigeria respectively. ${ }^{5}$

Ironically, all these countries are in sub-Saharan Africa that houses $70 \%$ of the global burden of HIV/AIDS infection. ${ }^{4}$ Thus, if the global target of reaching 15 million people with ARVs by the end of 2015 is to be achieved, the coverages in these countries have to improved. Barriers to HIV/AIDS treatment have to removed so as to improve access to the services and eventually the coverage. Such barriers differ from one country to another, hence the reason for choosing Nigeria for this study.

According to the World Health Organization, there were 35 million people infected with the AIDS virus in the world in 2013, out of which 1.5 million died, 2.1 million became newly infected, and 25 million cases $(70 \%)$ living in sub-Saharan Africa. ${ }^{4}$ Furthermore, the WHO has stated that HIV/AIDS has claimed more than 39 million lives from the beginning of the epidemic to date. ${ }^{6}$

In Nigeria, a national survey conducted in 2012 revealed a general population HIV prevalence rate of $3.4 \%$, or $5,740,356$ HIV infected persons, based on the projected 2012 total population of $168,834,000 .{ }^{6,7}$ Further analysis of the survey data revealed that the HIV prevalence was higher among the wealthier $(3.7 \%)$ than the poorer $(2.9 \%)$; higher among females $(3.5 \%)$ than males $(3.3 \%)$ and slightly higher in the rural areas (3.6\%) compared with the urban $(3.2 \%)$. In terms of regional distribution, the prevalence was highest in the South South region (5.5\%) and lowest in the South East (1.8\%) region. It was very interesting to also note that the prevalence was higher among respondents with primary and secondary education $(4.0 \%)$ as well as in those belonging to the age group 35-39 years old and those widowed (6.2\%). ${ }^{6}$

Important consideration here is that the national HIV policy require government to be committed towards ensuring that all Nigerians have access to quality health care and adequate treatment, including antiretroviral therapy. ${ }^{8}$ Moreover, the government in collaboration with partners is committed to the provision of affordable and accessible high-quality voluntary and confidential counselling and testing services in all nooks and corners of the country in line with international best practices. In doing so, special consideration will be given to vulnerable groups such as young people and women in the age group 20-24 years, commercial sex workers and those with tuberculosis. Preventive measures will be emphasized, including but not limited to, condom use and treatment of sexually transmitted infections (STIs). ${ }^{8}$

\section{Methods}

The literature search for this write-up was conducted electronically using the following key terms: HIV, AIDS, ARV, ART, Barriers, Nigeria, sub-Saharan Africa, Low-mid Income Countries. Peer reviewed articles and publications from 2010 to date, written in English were retrieved using search engines like Google Scholar, MEDLINE, PubMed etc. All articles published from 2009 and below and those written in other languages apart from English were excluded. Additionally, some of the methods used in those studies include case summary, review, systematic cleaning and validation of data, synthetic review of the literature, systematic review of the literature, qualitative descriptive cross sectional design, and cross sectional qualitative survey design with in-depth interview.

\section{Results}

The twenty articles identified from the literature search were based on different theoretical and conceptual frameworks which include, but not limited to 'Thematic content analysis' framework for the analysis of qualitative data, Models of care for HIV/AIDS control, Conceptual framework for intellectual property rules and practices, conceptual framework to establish a patent pool for ARVs, framework for community support and expert patient structures, and exploratory framework.

The HIV/AIDS control in Nigeria was established by the Federal Ministry of Health as a direct response to the global epidemic of the disease. From the first case of HIV/AIDS in 1986 to date, several steps have been taken by Government and partners to control the epidemic. Some of these steps include the establishment of the National Agency for the Control of AIDS (NACA) in the year 2000 as well as the adaptation of global public health initiatives like the US Presidential Emergency Plan For Aids Relief (PEPFAR) program. These steps have led to a lot of progress, albeit slowly, towards the tackling the scourge, as evidenced by the decrease in the disease prevalence from $5.8 \%$ in 2000 and 2003 , to $3.9 \%$ in $2005 ; 3.6 \%$ in 2007 ; and $3.4 \%$ in $2012 .{ }^{6}$ There has also been a substantial increase in the number of people living with HIV/AIDS (PLWHAs) who are on Antiretroviral Therapy (ART), including pregnant women. ${ }^{6}$

However, this progress is threatened by a number of barriers militating against access to HIV/AIDS program in the country. In order to learn about these barriers, an extensive literature review was carried out from peer-reviewed journals. A total of 20 peer reviewed articles consisting of both quantitative, qualitative and mixed methods studies undertaken in Nigeria and other developing countries and published in the last five years were obtained. Generally speaking, the barriers established from these studies could categorized into three: 
health systems related, patients related and community related.

The health systems related barriers are the largest and include, the soaring prices of antiretrovirals ${ }^{9,10}$, increasing numbers of clients in need of newer and expensive drugs without the necessary policy backing to manufacture and import generic versions by pharmaceutical companies in developing countries $^{11,12}$, reforms in the legal framework that had facilitated the production of cheap generic products in developing countries such as India due to implementation of WTO agreements ${ }^{13}$, strong intellectual property (IP) protection systems put in place by pharmaceutical companies. ${ }^{14,15}$

Other health system related barriers include the growing shortage of health manpower especially physicians due to high turnover $^{16,17,18}$, highly congested and poorly coordinated health care facilities ${ }^{19}$, knowledge gap among health care providers and side effects of the drugs. ${ }^{20,21}$

The patients related barriers include long distance to the service delivery points, transport costs, long waiting times, poor understanding of HIV, and PMTCT and direct cost and user fees. $^{22,23,24}$

The community related barriers include stigma and discrimination against people living with HIV/AIDS, gender discrimination against women living with the virus, interference with ART treatment by some religious leaders, ethical contentions due to high cost of antiretroviral drugs. $^{21,25,26,27,28}$

\section{Discussion}

As mentioned before, based on the literature review, the key barriers to HIV/AIDS treatment in developing countries of which Nigeria is one can be categorized into three namely: health systems related, patients related and community related. The health systems related include soaring prices of antiretrovirals especially the new second line drugs, shortage of health manpower, highly congested and dilapidated health care facilities, knowledge gap among health care providers and side effects of the drugs. The patients related barriers include long distance to the service delivery points, transport costs, long waiting times, poor understanding of HIV, and PMTCT and direct cost and user fees. The community related barriers include stigma and discrimination against people living with HIV/AIDS, gender discrimination against women living with the virus, interference with ART treatment by some religious leaders and ethical contentions due to high cost of antiretroviral drugs.

The strengths of this systematic literature review lies in the availability of adequate and recent information on the subject matter. However, the search strategy employed may not have captured all the studies related to the topic, thus introducing an information bias. Secondly, the exclusion criteria used may have excluded important studies, which would have produced different, results that the present ones. Nonetheless, several strengths were reported by the authors: the ability of the studies to collect large piece of qualitative and quantitative information from questionnaires and in-depth interviews, which was analyzed and gave rise to generalizable findings.
The key limitation encountered by several of the authors was related to the fact that the selected studies were rather heterogeneous in design, making comparison difficult. ${ }^{16}$

\subsection{Policy Implications}

The findings of this review have paved way for far-reaching recommendations for the consideration by policy makers and stakeholders. Some of these recommendations include ensuring that Pharmaceutical manufactures in India and other emerging economies continue to supply low priced quality-assured generic medicines ${ }^{13}$; organization of workshops for health care personnel working in HIV care and support centers ${ }^{21}$; ensuring adequate and reliable financing, research and development of new affordable ARVs for use in resource-poor countries ${ }^{11}$; and ensuring the flexibility of patent laws and adopting patent pooling as a viable strategy recommended by UNITAID to improve access to ARVs. ${ }^{14}$

The key Stakeholders include the National Agency for the control of AIDS (NACA), National HIV/AIDS control programme, World Health Organization, Centers for Disease Control and Prevention, PEPFAR Partners, other bilateral organizations, international NGOs, GFATM.

\subsection{Recommendations for Future Research}

In view of the multiethnic and multicultural nature of the Nigerian society, future researches are needed in this area in order to identify culture specific barriers, which will pave way for the specific and sustainable recommendations for policy makers and stakeholders. Few other recommendations for future research based on the articles reviewed include the need for more research on the intellectual property rights ${ }^{28}$; the need for more public enlightenment to reduce stigma and discrimination towards PLWHAs $^{21}$; the need for health workers to educate the PLWHAs on management of common side effects resulting from $\mathrm{ARVs}^{21}$; and the need for research to redesign current models for HIV care so as to address access issues particularly in resource-poor settings of sub-Saharan Africa. ${ }^{19}$

\section{Conclusions}

This literature review has shown that a number of barriers to HIV/AIDS treatment exist in Nigeria and elsewhere in the developing world. These barriers stand in the way of achieving the goals of the National HIV/AIDS policy, unless far reaching reforms are made in the way the services are rendered to the people. Furthermore, additional studies are needed in order to find culture specific barriers that would be amenable to local and sustainable solutions.

\section{References}

[1] Aliyu, M., Varkey, P., Salihu, H., Iliyasu, Z., \& Abubakar, I. (2010). The HIV/AIDS epidemic in Nigeria: progress, problems and prospects. Afr J Med Med Sci.39 (3): 233-9. Retrieved http://www.ncbi.nlm.nih.gov/pubmed/21416794. 
[2] CDC (2015). HIV Basics. Retrieved from http://www.cdc.gov/hiv/basics/index.html.

[3] UNAIDS (2014). AIDS and Global Health. Retrieved from data.unaids.org/pub/Report/2009/aidsandglobalhealth_en.pdf.

[4] WHO (2015a). HIV/AIDS Fact sheet $N^{\circ} 360$. Retrieved from http://www.who.int/mediacentre/factsheets/fs360/en/.

[5] WHO (2015b). Global Health Observatory (GHO) data. Retrieved from http://www.who.int/gho/hiv/epidemic_response/ART_text/en/.

[6] Federal Ministry of Health [Nigeria] (2013). National HIV \& AIDS and Reproductive Health Survey, 2012 (NARHS Plus). Federal Ministry of Health Abuja, Nigeria. Retrieved from https://www.academia.edu/9469489/NARHS_Plus_2012_Fina 1_18112013.

[7] Undata (2015). Nigeria Profile. Retrieved from https://data.un.org/CountryProfile.aspx?crName=NIGERIA.

[8] UNFPA Nigeria (2015). National Policy on HIV/AIDS. Retrieved from http://nigeria.unfpa.org/pdf/ntpol.pd.

[9] Lule, E. \& Haacker, M. (2012). The fiscal dimension of HIV/AIDS in Botswana, South Africa, Swaziland and Uganda. The World Bank. Retrieved from http://www.avert.org/hiv-aids-sub-saharan-africa.htm\#footnot e49 ydy85ph.

[10] Orsi, F., \& d'almeida, C. (2010). Soaring antiretroviral prices, TRIPS and TRIPS flexibilities: a burning issue for antiretroviral treatment scale-up in developing countries. Curr Opin HIV AIDS 5(3):237-41. doi: 10.1097/COH.0b013e32833860barrom http://www.ncbi.nlm.nih.gov/pubmed/20539080.

[11] Hoen, E.'t, Berger, J., Calmy, A., \& Moon, S. (2011). Driving a decade of change: HIV/AIDS, patents and access to medicines for all. Journal of the International AIDS Society, 14, 15. doi: 10.1186/1758-2652-14-15. Retrieved from http://www.ncbi.nlm.nih.gov/pmc/articles/PMC3078828/.

[12] Waning, B., Kyle, M., Diedrichsen, E., Soucy, L., Hochstadt, J., Bärnighausen, T., \& Moon, S. (2010). Intervening in global markets to improve access to HIV/AIDS treatment: an analysis of international policies and the dynamics of global antiretroviral medicines markets. Globalization and Health, 6 , 9. doi: 10.1186/1744-8603-6-9. Retrieved from http://www.ncbi.nlm.nih.gov/pmc/articles/PMC2883977/.

[13] Waning, B., Diedrichsen, E., \& Moon, S. (2010). A lifeline to treatment: the role of Indian generic manufacturers in supplying antiretroviral medicines to developing countries. $J$ Int AIDS Soc. 13:35. doi: 10.1186/1758-2652-13-35. Retrieved from http://www.ncbi.nlm.nih.gov/pubmed/20840741.

[14] Satyanarayana, K., \& Srivastava, S. (2010). Patent Pooling for Promoting Access to Antiretroviral Drugs (ARVs) - A Strategic Option for India. The Open AIDS Journal, 4, 41-53. doi: 10.2174/1874613601004020041. Retrieved from http://www.ncbi.nlm.nih.gov/pmc/articles/PMC2819698/.

[15] Babovic, S. and Wasan, K. M. (2011). Impact of the trade-related aspects of intellectual property rights (TRIPS) agreement on India as a supplier of generic antiretrovirals. J. Pharm. Sci., 100: 816-821. doi: 10.1002/jps.22326. Retrieved from http://www.ncbi.nlm.nih.gov/pubmed/20740678.

[16] Wouters, E., Van Damme, W., van Rensburg, D., Masquillier,
C., \& Meulemans, H. (2012). Impact of community-based support services on antiretroviral treatment programme delivery and outcomes in resource-limited countries: a synthetic review. BMC Health Services Research, 12, 194. doi: 10.1186/1472-6963-12-194. Retrieved from http://www.ncbi.nlm.nih.gov/pmc/articles/PMC3476429/.

[17] Ford, N., Calmy, A., \& Mills, E. J. (2011). The first decade of antiretroviral therapy in Africa. Globalization and Health, 7, 33 doi: 10.1186/1744-8603-7-33. Retrieved from http://www.ncbi.nlm.nih.gov/pmc/articles/PMC3192657/.

[18] Callaghan, M., Ford, N., \& Schneider, H. (2010). A systematic review of task- shifting for HIV treatment and care in Africa. Human Resources for Health, 8, 8. doi: 10.1186/1478-4491-8-8. Retrieved from http://www.ncbi.nlm.nih.gov/pmc/articles/PMC2873343/.

[19] Decroo, T., Rasschaert, F., Telfer, B., Remartinez, D., Laga, M., \& Ford, N. (2013). Community-based antiretroviral therapy programs can overcome barriers to retention of patients and decongest health services in sub-Saharan Africa: a systematic review. Int Health 5(3):169-79. doi: 10.1093/inthealth/iht016. Epub 2013 Jul 30.

[20] Colvin, C. J., Konopka, S., Chalker, J. C., Jonas, E., Albertini, J., Amzel, A. et al. (2014). A Systematic Review of Health System Barriers and Enablers for Antiretroviral Therapy (ART) for HIV-Infected Pregnant and Postpartum Women. PLoS ONE 9(10): e108150. doi:10.1371/journal.pone.0108150. Retrieved from

http://journals.plos.org/plosone/article?id=10.1371/journal.po ne. 0108150 .

[21] Okoye, U. O., Diekedie, A., and Afemikhe, O. A. (2015). Perceived Barriers to Accessing and Adhering to Antiretroviral Therapy by People Living with HIV/AIDS (PLWHAs) in Akwa Ibom State, Nigeria. Research on Humanities and Social Sciences ISSN (Paper) 2224-5766 ISSN (Online) 2225-0484 (Online) Vol.5, No.9. Retrieved from www.iiste.org/Journals/index.php/RHSS/article/download/.../2 3242 .

[22] Chindedza, M., Mutseyekwa, F., Chideme-Munodawafa, A. (2013). Perceived barriers to accessing and achieving adherence in antiretroviral therapy among HIV patients at a rural mission hospital in Zimbabwe. European Scientific Journal vol.9, No.24 ISSN: 1857 - 7881 (Print) e - ISSN 18577431. Retrieved from eujournal.org/index.php/esj/article/viewFile/1711/1700.

[23] Hodgson, I., Plummer, M. L., Konopka, S. N., Colvin, C. J., Jonas, E. et al. (2014). A Systematic Review of Individual and Contextual Factors Affecting ART Initiation, Adherence, and Retention for HIV-Infected Pregnant and Postpartum Women. PLoS ONE 9(11): el11421. doi: 10.1371/journal.pone.0111421.

[24] Beaulière, A., Le Maux, A., Trehin, C., \& Perez, F. (2010). Access to antiretroviral treatment in developing countries: Which financing strategies are possible? Rev Epidemiol Sante Publique. 58(3):171-9. doi: 10.1016/j.respe.2010.03.002. Epub 2010 Apr 28. Retrieved from http://www.ncbi.nlm.nih.gov/pubmed/20430553.

[25] Ullah, A. K. M. (2011). HIV/AIDS-Related Stigma and Discrimination: A Study of Health Care Providers in Bangladesh. JIAPAC 10(2):97-104. Retrieved from http://www.avert.org/hiv-aids-sub-saharan-africa.htm\#sthash.e PHsgEeT.dpuf. 
[26] Ellsberg, A. \& Betron, M. (2010). Preventing Gender-Based Violence and HIV: Lessons from the Field. AIDSTAR-One: Spotlight on Gender. Retrieved from http://www.avert.org/hiv-aids-sub-saharan-africa.htm\#sthash.e PHsgEeT.dpuf.

[27] Seeling, S., Mavhunga, F., Thomas, A., Adelberger, B., \& Ulrichs, T. (2014). Barriers to access to antiretroviral treatment for HIV-positive tuberculosis patients in Windhoek, Namibia.
International Journal of Mycobacteriology Volume 3, Issue 4, Pages 268-275. Retrieved from http://www.sciencedirect.com/science/article/pii/S2212553114 $000685 ? \mathrm{np}=\mathrm{y}$.

[28] Peterson, M. J. (2010). "Access to HIV Treatments in Developing Countries." International Dimensions of Ethics Education in Science and Engineering. Retrieved from www.umass.edu/sts/ethics. 